\title{
E-cigarettes for the management of nicotine addiction
}

\author{
This article was published in the following Dove Press journal: \\ Substance Abuse and Rehabilitation \\ 18 August 2016 \\ Number of times this article has been viewed
}

\section{Oliver Knight-West \\ Christopher Bullen}

The National Institute for Health Innovation, School of Population Health, The University of Auckland, Auckland, New Zealand
Correspondence: Christopher Bullen The National Institute for Health Innovation, School of Population Health, The University of Auckland, Private Bag 92019, AMC, Auckland II42, New Zealand

Email c.bullen@auckland.ac.nz
Abstract: In this review, we discuss current evidence on electronic cigarettes (ECs), a rapidly evolving class of nicotine delivery system, and their role in managing nicotine addiction, specifically in helping smokers to quit smoking and/or reduce the amount of tobacco they smoke. The current evidence base is limited to three randomized trials (only one compares ECs with nicotine replacement therapy) and a growing number of EC user surveys $(n=6)$, case reports $(n=4)$, and cohort studies $(n=8)$. Collectively, these studies suggest modest cessation efficacy and a few adverse effects, at least with the short-term use. On this basis, we provide advice for health care providers on providing balanced information for patients who enquire about ECs. More research, specifically well-conducted large efficacy trials comparing ECs with standard smoking cessation management (eg, nicotine replacement therapy plus behavioral support) and long-term prospective studies for adverse events, are urgently needed to fill critical knowledge gaps on these products.

Keywords: tobacco, smoking, nicotine, electronic cigarettes, cessation, addiction

\section{Introduction}

In the past decade, a novel product has emerged that has disrupted not only the smoking cessation therapeutics market but also the tobacco market. Electronic cigarettes (ECs), a class of battery-powered devices designed as an alternative to tobacco smoking, were invented by the Chinese engineer Hon Lik in the early 2000s. The product range has diversified considerably from the original devices, but all share the ability to heat a liquid mixture of propylene glycol, vegetable glycerine, water, flavorings, other additives, and commonly nicotine, sufficient to generate an aerosol for inhalation.

Despite the popular name suggesting a connection with tobacco cigarettes, apart from the appearance of some products (the so-called cigalikes), ECs are quite unlike conventional tobacco cigarettes in a number of important ways: they do not use tobacco, do not burn any material, and perhaps most importantly, do not produce smoke.

EC development has been extraordinarily rapid. In the UK, the number of current EC users increased from 400,000 in 2010 to 800,000 in 2012 and to 2.6 million by $2015,{ }^{1-3}$ such that they have replaced nicotine replacement treatment (NRT) as the most popular alternative to smoking for people trying to quit. ${ }^{2}$ Remarkably, ECs are also contributing to a decline in the sales of conventional tobacco cigarettes. ${ }^{4}$ There is also considerable product diversity: $>460$ EC brands and tens of thousands of liquid flavors were available in $2013,{ }^{5}$ and this is likely to have grown since then. 
The public health response to ECs has been mixed. Some tobacco control academics and advocates are concerned that widespread public EC use will renormalize the act of tobacco smoking just as it was not becoming the norm in some countries, will create a new and larger cohort of nicotine addicts, will act as a "gateway" to tobacco smoking for nonsmokers, will discourage current smokers from quitting completely, and will bring its own distinct but as yet unknown health risks in the same way tobacco smoking did, as a result of chronic exposure to a host of possible toxicants. ${ }^{6}$

On the other hand, EC proponents, leading academics and tobacco control advocates as well as EC users (known as vapers), suggest that $\mathrm{EC}$ use (vaping) will only contribute to making smoking less socially acceptable, will not appeal to never-smokers, will facilitate quitting tobacco, and is far safer than smoking. ${ }^{6,7}$ Many are in favor of "proportionate" regulation of ECs as medical devices to ensure the safety of vapers within a free market framework where ECs are able to evolve and compete with cigarettes as consumer products. ${ }^{6,7}$

Evidence on the strengths and limitations of each of these positions is accumulating, but still varies widely in quality. Such data need to be carefully and critically appraised as regulatory bodies decide what to do about this disruptive technology.

Reviews on the safety of ECs have concluded that, outside of pregnancy (for which no data are available), vaping is far safer, perhaps $95 \%$ safer, than smoking. ${ }^{6,89}$ Some health risks may emerge from the long-term use. Possible adverse health effects from long-term exposure to nicotine are worth exploring because of evidence from in vitro studies of carcinogenic potential, ${ }^{10}$ but the population-level evidence is not supportive. Other chemicals found in some EC vapors - formaldehyde, diethylene glycol, and heavy metals - are more likely to induce harm with long-term use. However, it is generally agreed that in the unlikely event of health effects occurring, they would be minor in comparison to the counterfactual of continued smoking.

In this review, we synthesize current evidence on ECs, their evolution and operation, and their role in helping smokers to quit and/or reduce the amount of tobacco they smoke. We discuss briefly the mechanisms by which ECs might do this and offer practical advice for clinicians around the use of ECs by their patients.

\section{Methods}

We searched Google Scholar and PubMed for studies published from 2004 to September 2015 using combinations of the following terms: electronic cigarettes, e-cigarettes,
ENDS, ECs, smoking cessation, efficacy, safety, and trials. We identified only three randomized controlled trials (RCTs), a Cochrane review and meta-analysis that included two of the three trials, six EC user surveys, four case reports, and eight cohort studies.

\section{Development of e-cigarettes}

There are a number of issues unique to ECs that present research challenges. These include wide and ongoing variation in product type, constituents and quality, and the rapid pace of device evolution. The first ECs closely resembled cigarettes and comprised a rechargeable battery and sealed, replaceable cartridge that contained the e-liquid. All products were manufactured in the People's Republic of China, with virtually all liquid produced in the same factory under different brand names. Most early model ECs were of poor production quality: batteries were often unreliable and cartridges leaked. These "first-generation" products, known as cig-a-likes, continue to be refined and updated at such pace that by the time a paper is published describing a particular model, it becomes obsolete. ${ }^{11}$

More recent "second- and third-generation" products are replaced at a similar pace. These ECs do not look like cigarettes. Some resemble large pens, while others are more distinct, but all have a refillable tank to hold the liquid (popularly referred to as juice or e-liquid). Some products, particularly the liquids, are now manufactured outside of the People's Republic of China, such as in Europe and the US, with tighter quality controls. The batteries are increasingly powerful, meaning they last longer between charges and can generate a greater nicotine concentration in the vapor. The users now have the option to modify different components of the device (for example, the battery voltage or the wick used to absorb the liquid) to alter the amount of nicotine in the vapor. Newer products are emerging that possess a heat control mechanism to prevent overheating the liquid, to avoid generating toxic by-products. A vast array of liquids is available, with thousands of possible flavors. There is also the option to include different ratios of propylene glycol to vegetable glycerine and nicotine concentrations.

Although only a fraction of the available devices and liquids have been tested, considerable variation has been detected in how much nicotine different products deliver to the vapor. ${ }^{12,13}$ Newer models contain fewer toxicants than older ones ${ }^{14}$ and enable vapers to absorb a greater amount of nicotine at a quicker rate. ${ }^{15}$ Indeed, in the hands of experienced vapers, some devices are able to match the nicotine delivery profile of a cigarette. ${ }^{16}$ 


\section{Mechanisms of action}

A nicotine delivery product that delivers nicotine to the brain as rapidly as a cigarette - but without toxic tobacco smoke - has long been the "holy grail" of NRT. ${ }^{17}$ Fasteracting NRT preparations have greater efficacy compared with slower-acting ones because they provide quicker dopamine release in the reinforcement pathway of the brain. ${ }^{18}$ The first ECs tested in research studies appeared to deliver nicotine largely through the buccal mucosa, with absorption speeds on a par with oral NRT such as nicotine gum and lozenge. ${ }^{19}$ However, more recent ECs appear to facilitate pulmonary absorption, with absorption in the blood equivalent to that with smoking tobacco. ${ }^{20}$ The faster mode of action should improve the management of cigarette withdrawal symptoms early on in a quit attempt and make stopping smoking easier.

Another factor unique to ECs is the level of sensory and behavioral replacement they offer. Even ECs that do not resemble conventional cigarettes have the potential to provide smokers with many of the tactile rituals, sensations, and behaviors associated with smoking (for example, preparation by the vaper, inhalation and exhalation of the EC vapor). Such factors are thought to play a key role in the addictive potential of cigarettes ${ }^{21}$ but are not sufficiently addressed by the existing NRT or other stop smoking treatments. However, nicotine is an essential part of the reinforcing aspect of these factors: without nicotine, they would not be "addictive".

\section{Evidence on efficacy of ECs for smoking cessation \\ Randomized controlled trials}

In 2014, a Cochrane systematic review of ECs for smoking cessation identified two RCTs with a combined sample size of 662 that compared ECs delivering nicotine with placebo (nonnicotine) ECs. ${ }^{22}$ One trial included low-level telephone support ${ }^{23}$ and one recruited smokers not intending to quit ${ }^{24}$ and both involved first-generation EC products with unreliable batteries and low nicotine content. Participants using an EC delivering nicotine were more likely to have ceased smoking for at least 6 months compared with those using placebo EC (relative risk [RR] 2.29, 95\% confidence interval [95\% CI] 1.05-4.96; placebo 4\% versus EC 9\%). Only one trial has yet been published that has compared ECs to nicotine replacement patches, finding no difference in abstinence rates at 6 months, although a clinically important difference cannot be excluded (RR 1.26, 95\% CI 0.68-2.34). ${ }^{23}$

In both trials, more people using ECs reduced their cigarette consumption by at least half compared with placebo ECs (RR 1.31, 95\% CI 1.02-1.68, two studies; placebo 27\% versus EC 36\%) and compared with patch (RR 1.41, 95\% CI 1.20-1.67).

The overall quit rates in the study comparing ECs with NRT ( $>90 \%$ of participants failed to quit at 6 months) were much lower than would be expected for a clinical trial. This could be explained by a range of factors such as the pragmatic study design and adherence to intention-to-treat analysis and early enthusiasm to take part in an EC trial that was tempered by either receiving a poor quality product (although among the "best" EC available at the time, there were several problems with it) or ending up in the NRT control arm. Another factor at play was the limited behavioral support received by the participants. A combination of behavioral support and stop smoking medication generates better chances of quitting than minimal support, with some evidence of a dose-response effect for treatment intensity. ${ }^{25}$ Using NRT over the counter with no support is no more effective than quitting without pharmaceutical aid. ${ }^{26}$

In a recent small trial $(\mathrm{n}=48)$ that did not meet the inclusion criteria for the Cochrane review, the researchers randomized smokers not interested in quitting to one of two types of second-generation ECs or a waitlist control (these participants received one of the ECs after 2 months). ${ }^{27}$ After 2 months, $35 \%$ of the participants in the two EC groups were abstinent compared with none in the waitlist group; at 8 months, $19 \%$ of the two EC groups were abstinent compared with $25 \%$ in the waitlist control (who by now had been vaping for 6 months).

\section{Cross-sectional studies}

A handful of studies have surveyed smoking behavior among the current vapers, ${ }^{28-34}$ but their findings require cautious interpretation due to self-selection bias: users with a more favorable experience of ECs are more likely than those who did not take to using them to complete such surveys. It is therefore not possible to tell from such studies the number of smokers who tried them but did not find them useful.

The majority of respondents to these surveys were reported to be former smokers who had used ECs daily for several months. In by far the largest study ( $\mathrm{n}=19,353), 81 \%$ of respondents were former smokers (mediation duration of abstinence of 1 month). ${ }^{34}$ Almost all were vaping daily (97\%) and using nicotine-containing e-liquid (96.5\%). The duration of EC use was longer in the former smokers than the current smokers (median of 11 months versus 8 months, respectively), while a higher proportion (56\%) of former smokers $(41 \%)$ than the current smokers were using thirdgeneration products. Fewer than $4 \%$ of the entire sample used first-generation devices. Data on smoking reduction across 
these studies generally did not quantify the extent of reduction, but vapers who were still smoking reported currently smoking fewer cigarettes since starting vaping.

\section{Case studies and cohort studies}

A small number of case reports (total $n=4$ ) suggested that ECs used regularly for at least 2 months helped smokers to quit for several months. ${ }^{35,36} \mathrm{~A}$ study that gave first-generation ECs to 40 smokers not interested in quitting for 6 months reported that $22.5 \%$ were abstinent for the last 30 days at 6 months and $12.5 \%$ were abstinent at 24 months. ${ }^{37}$ In a subsequent study with second-generation ECs $(n=50)$, the abstinence rates at 6 months were $36 \% .{ }^{38}$ Of 71 smokers who purchased an EC from a vape store, $41 \%$ were abstinent for the last 30 days at the 12-month follow-up and all were using second- or thirdgeneration products. ${ }^{39}$

In a nationally representative survey of 5,863 adults who smoked within the last year and tried at least once to quit, those who used an EC to try to quit were more likely than people who either used NRT bought over the counter or those who used no aid to quit for up to 6 months (adjusted odds ratio [aOR] $1.63,95 \% \mathrm{CI} 1.17-2.27$ and aOR $1.61,95 \% \mathrm{CI}$ 1.19-2.18, respectively). ${ }^{40}$

Other research has reached less favorable conclusions about the effect of ECs for smoking cessation. A longitudinal study of 949 smokers reported that baseline EC use was not associated with stopping smoking 12 months later. ${ }^{41}$ However, only 88 respondents used an EC at baseline, of whom nine $(10 \%)$ were abstinent at 1 year. It is also possible that smokers who try an EC find quitting tobacco more difficult than those who have successfully quit using other methods. The study also did not consider differences in the frequency of EC use (people were included as vapers even if they had tried an EC only once and never again in the 30 days preceding enrollment) or the type of EC used.

Data from the nationally representative samples of the International Tobacco Control study in the US, UK, Canada, and Australia (data collected from July 2010 to June 2011) reported that $85 \%$ of current EC users said that they helped them to quit smoking, although only $11 \%$ reported being abstinent. $^{42}$

Callers $(n=2,476)$ to a US state quitline were found to be more likely to report no smoking in the previous 30 days, 7 months after the initial contact, if they had never used an EC compared with people who had vaped either for a month or more or less than a month (abstinence rates $=31 \%, 21.7 \%$, or $16.6 \%$, respectively). ${ }^{43}$ However, this study has several limitations: it did not consider that people who try an EC could be among those who have greater difficulty quitting than those who do not. It also did not account for the observation that only half of the respondents stated that they used or tried an EC to help them quit tobacco.

In another study, Californian smokers were reported to be less likely to quit if they had ever used ECs compared with those who never used them (OR 0.51 , 95\% CI 0.30 0.87). ${ }^{44}$ However, while useful at highlighting "real-world" population-level findings, the study suffered from several limitations that make definitive conclusions difficult. First, smokers who tried an EC just once, without necessarily using it to try to quit, and who were still smoking at the follow-up were counted in the group who failed to quit using an EC. Second, the "control" group comprised entirely of smokers with no interest in ever using an EC.

Another study recruited 343 vapers who had been smoke free for the last 6 months, 319 people who both vaped and smoked at least once a week for the last 6 months, and 643 smokers with a follow-up 1 year later. ${ }^{45}$ Drop-out was high (27\%-31\% across the three groups), and the authors concluded that abstinence at 12 months was more likely among the people who enrolled as vapers versus those who enrolled as smokers (aOR 5.19, 95\% CI 3.35-8.02) but that smokers who started using ECs were not more likely to quit. Only 43 smokers at baseline started to use an EC (no data were reported on the type of product used or on the frequency of use), and of these, $34(80 \%)$ were abstinent from tobacco smoking at 12 months.

More recently, studies have explored explicitly the association between the type of EC, frequency of use, and quitting smoking. Among 1,643 smokers surveyed in the UK, 36\% reported any use of ECs at the 12-month follow-up. ${ }^{46}$ Relative to non-EC triers, only daily users of a second-generation (or better) product were more likely to be abstinent from tobacco at the follow-up ( $n=69$; OR 2.69, 95\% CI 1.48-4.89); nondaily use of second generation of EC and any use of first generation of EC were associated with either no increase or less likelihood of cessation. In a representative sample of 695 smokers from the US, vapers classified as intensive users (used ECs daily for at least 1 month) were much more likely than nonusers/triers (used ECs at most once or twice) to have quit at 1-2 years of follow-up (aOR 6.07, 95\% CI 1.11-33.18). ${ }^{47}$ Intermittent users (used ECs regularly, but not daily for $>1$ month) were not more likely to quit (aOR $0.31,95 \%$ CI $0.04-2.80)$. The reasons for the latter group's relative lack of success could include a lack of interest in 
complete tobacco cessation, perhaps using ECs only when smoking was not allowed, or were not using them sufficiently frequently to satisfy their addiction.

Cross-sectional and longitudinal studies that differ in their conclusions on the efficacy of ECs for smoking cessation also differ in key design features, such as not differentiating between experimental and sustained daily vaping, not accounting for potential greater difficulty in quitting among smokers who try an EC, not controlling for reasons of vaping (such as to quit smoking or not), and not examining the type of EC used. These factors would tend to reduce the likelihood that ECs will be beneficial for smoking cessation.

\section{Safety}

Evidence to date from randomized trials has found that the short-term use of ECs is not associated with health risks. $^{22-24}$ Population-level data suggest that long-term use of nicotine by itself is low in risk, so it is far more likely that any adverse health effects reported by EC users are due to the nonnicotine constituents of vapor. Until data from the long-term studies become available, knowledge of the health effects from toxicants in EC refill solutions, cartridges, and aerosols is currently the most realistic indication of the possible long-term health risks associated with ECs. Toxicants detected to date in a range of EC liquids and vapors have included tobacco-specific nitrosamines, aldehydes, metals, volatile organic compounds, phenolic compounds, polycyclic aromatic hydrocarbons, flavors, solvent carriers, and tobacco alkaloids. ${ }^{6,8,9}$ These findings highlight a lack of standards in the methods used to analyze EC aerosols. Just as the products differ widely in performance characteristics, so too there is no standardization of assessment of the toxic potential of ECs. Thus, some of the results could be under- or overestimating toxicant levels and exposures. Furthermore, while some of these data are now "historic", they also reveal the lack of standards in the manufacturing processes of much of the EC industry. Quality control is currently only driven by market forces. Notwithstanding these issues, the toxicant levels have almost without exception been at least a magnitude of order below those in tobacco smoke and within the accepted exposure limits. ${ }^{6,9}$

A further dimension to safety is that of the risk of harm at a population level. For example, concerns have been raised about the role of ECs as a gateway to smoking in children and young people, although to date the evidence is weak. ${ }^{6}$ Others have expressed concerns about growing tobacco industry involvement in the EC industry and the way the EC phenomenon may play into Big Tobacco's hands to sustain a market for tobacco. ${ }^{48}$

"Smart" regulations are clearly needed, not only to assure users of product safety but also to protect children from EC marketing, prohibit sales to minors, and establish a regimen where safer products are more price competitive than the most harmful ones. A wide range of regulatory arrangements is beginning to take shape in different jurisdictions to tackle the complex challenges ECs present. ${ }^{49}$

\section{Clinical advice}

Many people who smoke are likely to have tried ECs. Health care professionals should therefore be sufficiently informed about ECs to provide smokers who ask about ECs with accurate and balanced information. Stop-smoking specialists are often asked by their patients about the use of ECs, ${ }^{50,51}$ and the majority of patients seen in the mental health and drug addiction fields are tobacco smokers and likely to show interest in these products.

First, health care professionals should communicate that ECs have not been approved as cessation devices and there is limited evidence on the types or concentrations of potentially harmful chemicals they are exposed to when they use these products or their long-term efficacy and safety. ${ }^{52}$

Second, for smokers who have been unable to quit by using standard treatment or for smokers unlikely to try standard medications, health professionals should consider discussing the option of trying an EC. The American Heart Association recommends that health professionals should not discourage EC use when a person has made repeated efforts with conventional treatment yet failed and when conventional treatment is not tolerated or is rejected by a person who wants to use ECs to help them quit. ${ }^{53}$ For such people, it would be helpful to advise them to use a nicotine-containing EC in line with the evidence from the Cochrane review. ${ }^{22}$

If the patient decides to try ECs, he or she should be advised that vaping takes practice to ensure correct use. A period of familiarization may help increase the success of a quit attempt. Indeed, cutting down on the number of cigarettes smoked appears to happen with little effort when other sources of nicotine are used at the same time and is common in EC users. ${ }^{54}$ Health care providers should strongly encourage a goal of complete cessation (advising smokers that smoking even a few tobacco cigarettes is hazardous). However, for smokers unwilling to quit, advice to cut down should be provided, so long as this is done with a view to eventual quitting. 


\section{Discussion}

The best quality data available on ECs from two RCTs for the treatment of tobacco addiction suggest modest potential for helping smokers to quit but good potential for helping smokers to cut down. The quality and generalizability of these data are low, however, as the specific devices evaluated in the trials are no longer commercially available and, although analogous but improved products have replaced them, most vapers now use a distinctly different type of EC. Furthermore, only one of the trials ${ }^{23}$ included a comparison with other smoking cessation interventions (nicotine patches).

However, data from non-RCT studies and monitoring trends in product use suggest greater potential for ECs. Quit rates among smokers not interested in quitting are high, although it remains to be seen whether similar numbers would quit if they were not given ECs free of charge.

The possibility that second- and third-generation ECs have greater cessation efficacy is congruent with the findings that such products have a nicotine delivery profile closer to that of tobacco cigarettes. ${ }^{15,16}$ User behavior is also likely to play an important role; the finding that vapers "improve" at using ECs over time (reflected by greater nicotine absorption) might also explain in part why more intensive and frequent use has been associated with greater likelihood of stopping smoking. ${ }^{55,56}$ Conversely, it could also reflect that people who use them less are also less motivated to quit smoking.

Unlike other approaches to stopping smoking, there is a large community of users that offers EC users practical advice around how to vape and not smoke. There are over half a million YouTube videos on e-cigarettes and thousands of discussion forums, suggesting extensive demand for such information and communication. However, it is uncurated and of variable quality and reliability. The extent and nature of the role such support plays in helping people switch from smoking to vaping is an important area for future research.

A number of RCTs are currently underway investigating the efficacy of second-generation products. ${ }^{57,58}$ Data from these studies will not be available for several years. The onus will be on researchers to consider how they interpret their findings in the context of the EC landscape of the future. The pace of innovation may be slowing, but it would be unfortunate to conclude in a few years' time that data from these new RCTs have little bearing on what vapers might then be using.

Although challenging to conduct, such research is vital to inform health care providers and the public and regulatory authorities about how they should regard ECs. Many ques- tions remain as yet unanswered. In the meantime, millions of smokers have changed from known harmful tobacco smoking to less harmful vaping, in full or in part. Whether they will be able to continue to do so depends on how emerging evidence is interpreted by authorities and translated into policies and regulations.

\section{Disclosure}

Professor Bullen is the recipient of several grants from the Health Research Council of New Zealand for studies of e-cigarettes. The authors report no other conflicts of interest in this work.

\section{References}

1. Dockrell M, Morrison R, Bauld L, McNeill A. E-cigarettes: prevalence and attitudes in Great Britain. Nicotine Tob Res. 2013;15(10): 1737-1744.

2. Brown J, West R, Beard E, Michie S, Shahab L, McNeill A. Prevalence and characteristics of e-cigarette users in Great Britain: findings from a general population survey of smokers. Addict Behav. 2014;39(6):1120-1125.

3. ASH [webpage on the Internet]. Use of Electronic Cigarettes (Vapourisers) among Adults in Great Britain. Secondary Use of Electronic Cigarettes (Vapourisers) among Adults in Great Britain. 2015. Available from: http://www.ash.org.uk/files/documents/ASH_891.pdf. Accessed June 1, 2016.

4. Craver R [webpage on the Internet]. E-Cigs Will Overtake Traditional Tobacco Revenue at Reynolds in 2021. Secondary E-cigs Will Overtake Traditional Tobacco Revenue at Reynolds in 2021. 2013. Available from: http://www.journalnow.com/business/business_news/local/ analyst-projection-e-cigs-will-overtake-traditional-tobacco-revenue-at/ article_948674ca-1ca9-11e3-a0ae-0019bb30f31a.html. Accessed June 1, 2016.

5. Zhu S-H, Sun JY, Bonnevie E, et al. Four hundred and sixty brands of e-cigarettes and counting: implications for product regulation. Tob Control. 2014;23(suppl 3):iii3-iii9.

6. Hajek P, Etter JF, Benowitz N, Eissenberg T, McRobbie H. Electronic cigarettes: review of use, content, safety, effects on smokers and potential for harm and benefit. Addiction. 2014;109(11):1801-1810.

7. Etter JF. Should electronic cigarettes be as freely available as tobacco? Yes. BMJ. 2013;346:f3845.

8. Farsalinos KE, Polosa R. Safety evaluation and risk assessment of electronic cigarettes as tobacco cigarette substitutes: a systematic review. Ther Adv Drug Saf. 2014;5(2):67-86.

9. Public Health England. E-Cigarettes: An Evidence Update. London: Public Health England; 2015.

10. Sanner T, Grimsrud TK. Nicotine: carcinogenicity and effects on response to cancer treatment - a review. Front Oncol. 2015;5:196.

11. Bullen C, Knight-West O. Issues in regulating E-cigarette clinical research. Clin Res Reg Affairs. 2015;32(1):1-5.

12. Goniewicz ML, Kuma T, Gawron M, Knysak J, Kosmider L. Nicotine levels in electronic cigarettes. Nicotine Tob Res. 2013;15: $158-166$.

13. Goniewicz ML, Hajek P, McRobbie H. Nicotine content of electronic cigarettes, its release in vapour and its consistency across batches: regulatory implications. Addiction. 2014;109(3):500-507.

14. Laugesen $M$. Nicotine and toxicant yield ratings of electronic cigarette brands in New Zealand. N Z Med J. 2015;128(1411):77-82.

15. Farsalinos KE, Spyrou A, Tsimopoulou K, Stefopoulos C, Romagna G, Voudris V. Nicotine absorption from electronic cigarette use: comparison between first and new-generation devices. Sci Rep. 2014;4:4133. 
16. Talih S, Balhas Z, Eissenberg T, et al. Effects of user puff topography, device voltage, and liquid nicotine concentration on electronic cigarette nicotine yield: measurements and model predictions. Nicotine Tob Res. 2015;17(2):150-157.

17. Russell MA. The future of nicotine replacement. Br JAddict. 1991;86(5): 653-658.

18. Stead LF, Perera R, Bullen C, et al. Nicotine replacement therapy for smoking cessation. Cochrane Database Syst Rev. 2012;11:CD000146.

19. Bullen C, McRobbie H, Thornley S, Glover M, Lin R, Laugesen M. Effect of an electronic nicotine delivery device (e cigarette) on desire to smoke and withdrawal, user preferences and nicotine delivery: randomised cross-over trial. Tob Control. 2010;19(2):98-103.

20. Vansickel AR, Eissenberg T. Electronic cigarettes: effective nicotine delivery after acute administration. Nicotine Tob Res. 2013;15(1): 267-270.

21. Przulj D, McRobbie H, Hajek P. The effect of sensorimotor replacement on smoking cessation and craving. Open Add J. 2012;5:41.

22. McRobbie H, Bullen C, Hartmann-Boyce J, Hajek P. Electronic cigarettes for smoking cessation and reduction. Cochrane Database Syst Rev. 2014;12:CD010216.

23. Bullen $C$, Howe $C$, Laugesen $M$, et al. Electronic cigarettes for smoking cessation: a randomised controlled trial. Lancet. 2013;382(9905):1629-1637.

24. Caponnetto P, Campagna D, Cibella F, et al. Efficiency and safety of an eLectronic cigAreTte (ECLAT) as tobacco cigarettes substitute: a prospective 12-month randomized control design study. PLoS One 2013;8(6):e66317.

25. Stead LF, Lancaster T. Combined pharmacotherapy and behavioural interventions for smoking cessation. Cochrane Database Syst Rev. 2012;10:CD008286.

26. Kotz D, Brown J, West R. 'Real-world' effectiveness of smoking cessation treatments: a population study. Addiction. 2014;109(3):491-499.

27. Adriaens K, Van Gucht D, Declerck P, Baeyens F. Effectiveness of the electronic cigarette: an eight-week Flemish study with six-month follow-up on smoking reduction, craving and experienced benefits and complaints. Int J Environ Res Public Health. 2014;11(11):11220-11248.

28. Etter JF. Electronic cigarettes: a survey of users. BMC Public Health. 2010;10:231

29. Etter JF, Bullen C. Electronic cigarette: users profile, utilization, satisfaction and perceived efficacy. Addiction. 2011;106(11):2017-2028.

30. Goniewicz ML, Lingas EO, Hajek P. Patterns of electronic cigarette use and user beliefs about their safety and benefits: an Internet survey. Drug Alcohol Rev. 2013;32(2):133-140.

31. Foulds J, Veldheer S, Berg A. Electronic cigarettes (e-cigs): views of aficionados and clinical/public health perspectives. Int J Clin Pract. 2011;65(10):1037-1042.

32. Dawkins L, Turner J, Roberts A, Soar K. 'Vaping' profiles and preferences: an online survey of electronic cigarette users. Addiction. 2013;108(6):1115-1125

33. Siegel MB, Tanwar KL, Wood KS. Electronic cigarettes as a smoking-cessation: tool results from an online survey. Am J Prev Med. 2011;40(4):472-475.

34. Farsalinos K, Romagna G, Tsiapras D, Kyrzopoulos S, Voudris V. Characteristics, perceived side effects and benefits of electronic cigarette use a worldwide survey of more than 19,000 consumers. Int J Environ Res Public Health. 2014;11(4):4356-4373.

35. Caponnetto P, Polosa R, Russo C, Leotta C, Campagna D. Successful smoking cessation with electronic cigarettes in smokers with a documented history of recurring relapses: a case series. J Med Case Rep. 2011;5:585.

36. Farsalinos KE, Romagna G. Chronic idiopathic neutrophilia in a smoker, relieved after smoking cessation with the use of electronic cigarette: a case report. Clin Med Insights Case Rep. 2013;6:15-21.

37. Polosa R, Caponnetto P, Morjaria JB, Papale G, Campagna D, Russo C. Effect of an electronic nicotine delivery device (e-Cigarette) on smoking reduction and cessation: a prospective 6-month pilot study. BMC Public Health. 2011;11:786.
38. Polosa R, Caponnetto P, Maglia M, Papale G, Campagna D, Russo C. Success rates with nicotine personal vaporizers: a prospective 6-month pilot study of smokers not intending to quit. BMC Public Health. 2014; $14: 1159$

39. Polosa R, Caponnetto P, Cibella F, Le-Houezec J. Quit and smoking reduction rates in vape shop consumers: a prospective 12-month survey. Int J Environ Res Public Health. 2015;12(4):3428-3438.

40. Brown J, Beard E, Kotz D, Michie S, West R. Real-world effectiveness of e-cigarettes when used to aid smoking cessation: a cross-sectional population study. Addiction. 2014;109(9):1531-1540.

41. Grana RA, Popova L, Ling PM. A longitudinal analysis of e-cigarette use and smoking cessation. JAMA Intern Med. 2014;174(5): 812-813.

42. Adkison SE, O’Connor RJ, Bansal-Travers M, et al. Electronic nicotine delivery systems: international tobacco control four-country survey. $\mathrm{Am}$ J Prev Med. 2013;44(3):207-215.

43. Vickerman KA, Carpenter KM, Altman T, Nash CM, Zbikowski SM. Use of electronic cigarettes among state tobacco cessation quitline callers. Nicotine Tob Res. 2013;15(10):1787-1791.

44. Al-Delaimy WK, Myers MG, Leas EC, Strong DR, Hofstetter C. E-cigarette use in the past and quitting behavior in the future: a population-based study. Am J Pub Health. 2015;105(6):1213-1219.

45. Manzoli L, Flacco ME, Fiore M, et al. Electronic cigarettes efficacy and safety at 12 months: cohort study. PLoS One. 2015;10(6): e0129443.

46. Brose LS, Hitchman SC, Brown J, West R, McNeill A. Is the use of electronic cigarettes while smoking associated with smoking cessation attempts, cessation and reduced cigarette consumption? A survey with a 1-year follow-up. Addiction. 2015;110(7):1160-1168.

47. Biener L, Hargraves JL. A longitudinal study of electronic cigarette use in a population-based sample of adult smokers: association with smoking cessation and motivation to quit. Nicotine Tob Res. 2015;17(2): 127-133.

48. Chapman S. E-cigarettes: the best and the worst case scenarios for public health. BMJ. 2014;349:g5512.

49. Bullen C. Regulatory policy and practical issues arising from a disruptive innovation: a public health perspective on e-cigarettes. $A J W H$. 2016;11:1.

50. Beard E, Brose LS, Brown J, West R, McEwen A. How are the English Stop Smoking Services responding to growth in use of electronic cigarettes? Patient Educ Couns. 2014;94(2):276-281.

51. Hiscock R, Goniewicz ML, McEwen A, et al. E-cigarettes: online survey of UK smoking cessation practitioners. Tob Induced Dis. 2014; 12(1):13.

52. US Food and Drug Administration [webpage on the Internet]. News and Events; Public Health Focus. 2016. Available from: http://www. fda.gov/NewsEvents/PublicHealthFocus/ucm172906.htm. Accessed April 19, 2016.

53. Bhatnagar A, Whitsel LP, Ribisl KM, et al. Electronic cigarettes: a policy statement from the American Heart Association. Circulation. 2014;130(16):1418-1436.

54. Farsalinos KE, Romagna G, Voudris V. Factors associated with dual use of tobacco and electronic cigarettes: a case control study. Int J Drug Policy. 2015;26(6):595-600.

55. Hajek P, Goniewicz ML, Phillips A, Myers Smith K, West O, McRobbie H. Nicotine intake from electronic cigarettes on initial use and after 4 weeks of regular use. Nicotine Tob Res. 2015;17(2):175-179.

56. Farsalinos KE, Spyrou A, Stefopoulos C, et al. Nicotine absorption from electronic cigarette use: comparison between experienced consumers (vapers) and naïve users (smokers). Sci Rep. 2015;5:11269.

57. Fraser D, Borland R, Gartner C. Protocol for a randomised pragmatic policy trial of nicotine products for quitting or long-term substitution in smokers. BMC Public Health. 2015;15:1026.

58. Lopez AA, Cobb CO, Yingst JM, et al. A transdisciplinary model to inform randomized clinical trial methods for electronic cigarette evaluation. BMC Public Health. 2016;16(1):217. 


\section{Publish your work in this journal}

Substance Abuse and Rehabilitation is an international, peer-reviewed, open access journal publishing original research, case reports, editorials, reviews and commentaries on all areas of addiction and substance abuse and options for treatment and rehabilitation. The manuscript management system is completely online and includes a very quick and fair peer-review system. Visit http://www.dovepress.com/testimonials.php to read real quotes from published authors.

Submit your manuscript here: https://www.dovepress.com/substance-abuse-and-rehabilitation-journal 